\title{
Do WHO pharmaceutical pricing guidelines help low- and middle-in- come countries to price medicines rationally?
}

Mehrnaz Kheirandish ${ }^{1}$

${ }^{1}$ Director-General, Department for Assessment and Control of Prescribing and Use of Medicines and Health Products, Food and Drug Administration, Ministry of Health and Medical Education, Tehran, Islamic Republic of Iran. (Correspondence to: Mehrnaz Kheirandish: mehrnazkheirandish@gmail. com).

Citation: Kheirandish M. Do WHO pharmaceutical pricing guidelines help low- and middle-income countries to price medicines rationally? East Mediterr Health J. 2020;26(4):372-373. https://doi.org/10.26719/2020.26.4.372

Received: 15/06/19; accepted: 06/11/19

Copyright (C) World Health Organization (WHO) 2020. Some rights reserved. This work is available under the CC BY-NC-SA 3.0 IGO license (https:// creativecommons.org/licenses/by-nc-sa/3.o/igo).

Pharmaceutical expenditure accounts for a large share of health expenditure, and one of the main challenges in the countries with limited resources is selection of the most appropriate pharmaceutical pricing method. There are many approaches to pharmaceutical pricing as well as a variety of pharmaceutical production technologies; therefore, health systems often face difficulties in selecting the best methods that fit their goals. For developing countries, setting affordable medicine prices to ensure people can access the medicines they need, while at the same time supporting the domestic pharmaceutical industry to ensure a sustainable supply chain is a challenge for their health systems (1). Therefore, practical guidelines are needed that can help low- and middle-income countries by explaining steps for pharmaceutical pricing (2). Equitable access to medicines is a global concern and will not be guaranteed unless medicines are available at a price that the consumer can afford (3). Health systems should ensure that people are able access and buy essential medicines when they need them and in the quantity they need. Hence, not only is rational pharmaceutical pricing required, but also other supportive policies such as insurance coverage or subsidy.

Because of the variety, ambiguity and complexity of the different pharmaceutical pricing methods, countries of the World Health Organization (WHO) Eastern Mediterranean Region need guidelines to explain each of these methods, including their implementation, strengths, limitations and requirements in different country settings. In 2015, WHO developed its guidelines on country pharmaceutical pricing policies to help countries, especially low- and middle-income countries, make appropriate decisions on methods for pricing medicines (4). However, there are still unanswered questions.

First, the high expenditure on pharmaceuticals is not only because of the high cost of medicines, but also because of high consumption (5). Therefore, the total pharmaceutical expenditure needs to be separated from the price of medicines, as each requires different policies. High consumption of medicines could occur because of the irrational use of medicines as a result of self-medication or over-prescribing by physicians. The routinely adopted pricing policies, such as the cost plus method, are usually more effective if the main aim is to control expenditure. Implementation of an essential medicines list and evidence-based guidelines which are not directly linked to pricing policies $(6,7)$ should be complemented with pricing policies when the main concern is high and irrational consumption.

Second, consideration of the technology for the production of medicines is important in choosing the pricing method. For example, most of the expensive medicines are new and/or specialized medicines with no available generic forms. Controlling the price of these medicines through generally recommended policies such as cost plus or reference pricing is difficult because often valid reference prices are limited and the production costs are unclear to policy-makers (8).

Third, some defined methods, such as generic substitution or health technology assessment, can be used to control medicines prices indirectly (9). These methods have no clear role in setting the price of medicines directly. Therefore, they should not be listed as pricing strategies, but rather as price control strategies. For example, a country might use health technology assessment to reduce the medicine price when the stated price is more than its value according to the results of health technology assessment (10).

Fourth, it is important to distinguish between valuebased pricing, mentioned in the WHO guideline, from health technology assessment (4). Defining the value of a medicine is difficult and not a useful way of pricing medicine. For example, if a medicine is life-saving, should it be priced highly? If yes, then this will have major implications for the health system. Also, it is worth noting that value-based pricing can lead to companies determining a high price for their products.

Fifth, one of the pricing methods recommended in the WHO guideline and which is widely used globally is external reference-based pricing. In most countries, especially European countries, external reference-based pricing has been used to first control parallel imports and then pharmaceutical pricing (11). However, for low- and middle-income countries, particularly countries in the Eastern Mediterranean Region, the main goal of using 
this method is to price medicines. Therefore, the correct implementation of this method is critical due to the many different country settings. For example, choosing reference countries, determining valid prices and maintaining the same price in neighbouring countries are important considerations. In addition, having adequate cooperation and coordination between countries in the same region is necessary if using this method.

In conclusion, a guideline on pharmaceutical pricing methods, to be more useful, should provide clear stepby-step advice on how to implement pricing approaches in practice, so that the dos and don'ts of each approach are clear. Such a guideline should also avoid general recommendation of methods that are subject to wide interpretation and misuse, for example, value-based pricing. In addition, it is important to separate the discussion of tools and resources that can help price setting (for example, health technology assessment) from the pricing approaches. Ideally, a guideline on pharmaceutical pricing methods should help countries with different health system capacity and resources select pricing approaches that assist them in enhancing access to medicines and improving universal health coverage.

\section{References}

1. Kheirandish M, Rashidian A, Kebriaeezade A, Cheraghali AM, Soleymani F. A review of pharmaceutical policies in response to economic crises and sanctions. J Res Pharm Pract 2015;4(3):115-22. http://dx.doi.org/10.4103/2279-042X.162361

2. Nguyen TA, Knight R, Roughead EE, Brooks G, Mant A. Policy options for pharmaceutical pricing and purchasing: issues for low-and middle-income countries. Health Policy Plan. 2015;30(2):267-80. https://doi.org/10.1093/heapol/czt105

3. Cameron AM. Understanding access to medicines in low- and middle-income countries through the use of price and availability indicators. Utrecht University; 2013 Jan 10.

4. WHO guideline on country pharmaceutical pricing policies. Geneva: World Health Organization; 2015 (https://apps.who.int/iris/ bitstream/handle/10665/153920/9789241549035_eng.pdf?sequence=1, accessed 1 April 2020).

5. Pharmaceutical expenditure. In: Health at a glance: Europe 2010. Paris: OECD Publishing; 2010. http://dx.doi.org/10.1787/health_ glance-2010-en

6. Tele P, Groot W. Cost containment measures for pharmaceuticals expenditure in the EU countries: a comparative analysis. Open Health Services Policy J. 2009;2(1):71-83.

7. Hogerzeil HV. The concept of essential medicines: lessons for rich countries. BMJ. 2004;329(7475):1169-72. http://dx.doi. org/10.1136/bmj.329.7475.1169

8. Connors J. Future sustainability of pharmaceutical expenditure. Spending review 2017. Dublin: Department of Public Expenditure \& Reform; 2017 (https://assets.gov.ie/7270/e95c3f767abb40c2acca72e81bd94184.pdf, accessed 1 April 2020).

9. Paris V, Belloni A. Value in pharmaceutical pricing. OECD Health Working Paper, No. 63. Paris: OECD Publishing; 2013. http:// dx.doi.org/10.1787/5k43jc9v6knx-en

10. Koh L, Glaetzer C, Li SC, Zhang M. Health technology assessment, international reference pricing, and budget control tools from China's perspective: what are the current developments and future considerations? Value Health Reg Issues. 2016;9:15-21. http:// dx.doi.org/10.1016/j.vhri.2015.06.004

11. Geng D, Saggi K. External reference pricing policies, price controls, and international patent protection. Nashville: Department of Economics, Vanderbilt University; 2015 (https://my.vanderbilt.edu/kamalsaggi/files/2011/o8/ERP-Geng-Saggi-Sept-16.pdf, accessed 1 April 2020). 